\title{
Imperatives for Academia-Industry Collaboration in Building Construction Research in Ghana
}

\author{
David Mbabil Dok Yen' ${ }^{1}$ Emmanuel Adinyira ${ }^{2}$, Abdul Manan Dauda1 \\ ${ }^{1}$ Department of Building Technology, Tamale Technical University, Tamale, Ghana \\ ${ }^{2}$ Department of Building Technology, Kwame Nkrumah University of Science and Technology, Kumasi, Ghana \\ Email: dydavid@tatu.edu.gh, adinyira.cap@knust.edu.gh,ddabdul-manan@tamale.edu.gh
}

How to cite this paper: Dok Yen, D.M., Adinyira, E. and Dauda, A.M. (2018) Imperatives for Academia-Industry Collaboration in Building Construction Research in Ghana. Journal of Building Construction and Planning Research, 6, 185-197. https://doi.org/10.4236/jbcpr.2018.64013

Received: August 9, 2018

Accepted: October 28, 2018

Published: October 31, 2018

Copyright $\odot 2018$ by authors and Scientific Research Publishing Inc. This work is licensed under the Creative Commons Attribution International License (CC BY 4.0).

http://creativecommons.org/licenses/by/4.0/ cc) () Open Access

\begin{abstract}
Academia and industry research enables researchers to conduct research projects that are more relevant to current business practices and context. Although, several construction research works have been done by the academics in the tertiary institutions in Ghana, it is sad to know that, a large number of these research works have not moved from the pure stage to the applied stage. This study seeks to establish the imperative of academia and industry collaboration in building research in Ghana. A total of 116 construction practising professionals consisting of Ghana Institute of Construction (GIOC) corporate members (QS, Architects, Engineers and so on) from the industry, and academics from tertiary academic institutions (That's, Lecturers from KNUST and UEW) that run postgraduate construction programmes in Ghana as at February 2016 constituted the respondents for this study. Census and systematic sampling techniques were used for the sampled population. Descriptive statistics was employed in the data analysis for the mean and standard deviation (SD) score values of variables. The most imperatives for academia and industry collaboration were found to be: ensuring research findings solve socio-economic and development problems, the intermittent collapse of buildings, support for the local industries to produce quality materials locally to feed the construction industry, proper contract documentations and administration. This research would bring to light the urgent issues in the construction industry that calls for greater collaboration between the academia and industry in Ghana. It reveals a deeper understanding on the need for collaborative research in the Ghanaian construction industry, by providing the most imperatives to academia-industry collaborative research in Ghana.
\end{abstract}




\section{Keywords}

Imperatives, Academia and Industry, Collaboration, Building Construction, Research, Ghana

\section{Introduction}

Academia and Industry collaborations can simply be explained as the pairing of discovery and dissemination of knowledge for the creation of products and services [1]. When properly structured, the final reward of the collaboration of the public and society far exceeds the combined effort of the partners; it leads to improvement on the standards of living, economic growth, and improvement in humanity and intellectual development [1]. Nevertheless, collaboration often comes with some challenges in terms of costs and reward to all participants. Academia has the benefit of getting more funding from industry through collaboration [2]. The Industry on the other hand has the benefit of getting access to innovation and discoveries from academia research [2].

The Ghanaian construction industry is faced with many challenges with some of the reasons being due to lack of formal collaboration between the academia and industry in the area of construction research. The academia is faced with constraints regarding resources, funding, material, laboratories, equipment and so on for research, teaching and training of professionals, yet the industry has the ability to help in the provision of such facilities. The numerous research works ongoing in the academic institutions every year in the tertiary institutions are not fully utilised by the industry. Yet the industry is faced with several challenges such as: the collapse of buildings intermittently in Kumasi and Accra, the major capital cities in Ghana, revealing the high degree of incompetencies and problems within the Ghanaian construction industry that calls for attention and redress by all stakeholders in the industry to forestall any unforeseen calamity [3]. In realistic terms, the academia sometimes is unable to identify the actual needs or problems faced by the industries; however, the industry does not share their problems or needs with the academia to address. Nevertheless, it is an established fact that the collaborative effort between the academia and industry can make meaningful contribution to improving industry performance of nations [4].

The objective of this research seeks to establish the imperatives for academia industry collaborative research in the construction industry which would go a long way to foster the need for stronger construction research collaboration between the academia and industry in Ghana.

\section{Nature of the Ghanaian Construction Industry}

The Academia and Industry are the main key players in the Ghanaian construction industry. The academia is made up of Tertiary Institutions that is; Universi- 
ties, Technical Universities \& Polytechnics Building and Civil Engineering Faculties, Research institutions, for example, Building and Road Research Institute (BRRI), Council for Science and Research Industry (CSRI) and so on, Technical and vocational schools that run building craft programmes.

The role of the academia is teaching and training of construction professionals (i.e., Quantity Surveyors, Architects, engineers, etc.) to feed the construction industry. The academia also conducts construction research to contribute to knowledge, innovations, problem-solving, etc. to the industry and society as a whole.

Whilst, the industry is also made up of Professional Bodies such as; Ghana Institute of Surveyors (GHIS), Ghana institute of Architects (GIA), Ghana Institutes of Construction (GIOC), Ghana Institute of Engineers (GHIE), and so on consisting of (Quantity Surveyors, Architects, Engineers, and so on and so forth), also, industry players such as; government, donors, contractors, consultants, Engineers, manufacturers, suppliers, skill and unskilled labour, etc., the Laboratory's, survey departments, Land Commission and Town and Country Planning. The industry is responsible for the construction, consulting, supervision, monitoring, contract documentations, etc. that are all aspects of production of construction products in the country, they are also responsible for all paper documentations, testing, and consulting and so on that are from pre-contract and post-contract stage in construction. They are responsible for absorbing or employing the professional's trained from the academia and converting their theoretical knowledge acquired from the academia into real problem solving for the production of construction products.

However, the Ghanaian construction industry is faced with many challenges with some of the reasons been due to lack of formal collaboration between the academia and the industry in the area of construction research.

\section{Theoretical Framework}

Researcher collaboration may come as a result of several diverse reasons among partners. Some of these may be to enhance the visibility and recognition of research partners [5]. To enable partners get the opportunity to use equipment they cannot afford or get access to, but through the benefit of collaboration [6] and [7], or for the purpose of obtaining some new ideas or innovation as well as expertise needed for research [8] and [9]. According to [10], significant influencing factors for collaborative working may include partners having a common goal and priorities, by engagement of stakeholders, common vision, developing trusting relationships among partners, having a good form of communication and setting a clear definition of procedures for collaboration and interoperability standards. Also in a similar view, culture dimension, working environment factors, the structure of collaboration, equipment for use, process factors, availability of technology, communication and resources were found to be the influencing factors for collaboration [11] [12] [13] [14]. 
Nevertheless, effective collaboration does not necessarily result from the implementation of information technology systems alone [15] and [16], unless the organisational/institutions and human resources issues are taken into consideration during implementations. Therefore, methods based on pure information technology during collaboration are bound to be ineffective [10].

Collaborative research instructs partners to contribute with the understanding to adjusting to suit the research methodologies at any point in time when the need arises. It also requires the combined efforts in reviewing to solve diverse problems when they arise. Again, partners in collaborative research may jointly fund research projects or seek sponsorship together [17]. Also, collaborative approach is necessary to combine the energies of the construction industry and institutions to coordinate research effort for the future needs of the construction industry [4]. An organisation may also go into collaboration due to pressure demand by their stakeholder groups, customer demand or authority regulations [18].

\subsection{Types of Imperatives for Collaborative Research}

According to [19] the imperatives for collaborative research includes among others such as, asymmetry reciprocity, stability, economic efficiency, legitimacy collaboration and so on.

\subsubsection{Asymmetry Collaboration}

[19] referred to asymmetry as the kind of collaborative forces that drive organisations/institutions to venture into collaboration with their main agender been to have dominion or control over their partners (organisations/institutions) or its resources such as technology, raw materials, expertise, and so on. Asymmetry often has a relation with unequal distribution of authority/power among organisations/institutions even when they are into collaborative relationship. This form of collaboration, therefore, creates the room for some form of domination or authority of one party over other organisations or institutions.

\subsubsection{Reciprocity Collaboration}

Reciprocity is the reverse of asymmetry for collaboration. [19] stated that the reasons for reciprocity rely on the emphasis of coordination, cooperation, and collaboration between institutions/organisations, more than the domination, dominance, and control of organisation over each other [20]. The determinants of this kind of collaboration are the motivation to join forces for the principles of pursuing a mutual end, benefit or interest among partners; all parties deliver the power to function equally and no governing body/institution has dominion over the other [19].

Generally, collaboration offers partners better ways of doing things, increase productivity and services [21] and [22].

[23] study showed that academia and industry collaborative research projects can produce more scientific outputs compared to those without the partnership; 
however, it was based on the condition of intense and well executed research. One of the potential benefits of collaborative research is the capability of producing practical knowledge through effective synergy between academics and practitioners [24]. [25] pointed out that research collaborations between universities and industries provide opportunities to enhance knowledge and to advance technologies. Also, research collaborations between academic researchers and industry practitioners enable researchers to conduct research projects that are more relevant to current business practices and context [24]. Moreover, when practitioners who have participated in collaborative research return to their organisations, they could be a focal point in disseminating and implementing the research results within their organisations. From an academic perspective, researchers involved in collaboration tend to produce more publications and their publications have more acceptance rates than other researchers due to the enhanced competence [26].

\section{Methodology}

The compass of this research was constrained to a workable representation of the population by capturing only practising professionals directly within construction academia/industry in Ghana. Academics from tertiary institutions that run postgraduate construction programmes in Ghana as of February 2016 were sampled for this study. The Building Technology Department of KNUST-Kumasi was selected because they run $\mathrm{MSc} / \mathrm{MPhil} / \mathrm{PhD}$ in construction management and Building Technology, and also the Department of Construction and Wood Technology, University of Education, Winneba-Kumasi was selected as part of the sub-population sample for Academia because it also run's MPhil Construction Technology and M. Tech.-Construction. These two were selected from the academia, because they are responsible for training and conducting higher level construction research works more frequent which can be applied or implemented in the construction industry. Therefore, they are in the position to make effective contributions to this research study. The sub-population sample of the industry consisted of corporate members of the Ghana Institute of Construction (GIOC) as part of this research, since this is the only professional body in Ghana that brings together all the professionals from across all sectors that are directly linked to the construction industry (such as, Quantity Surveyors, Architects, Construction Engineers, and so on). These are professionals who supervise the day-to-day construction activities in the Ghanaian construction industry. The logic behind the selected respondents was to ensure that the study has a representation of the major stakeholders in construction academia/industry that can make significant contributions to the aim and objective of this study.

\subsection{Population Sample for the Study}

Considering the nature of this research, the sample frame was consist of a population of practising professionals such as practising professionals in the building 
construction industry (i.e., Quantity Surveyors, Architects, Engineers, etc.) and, practising construction researchers such as lecturers in tertiary postgraduate institutions who run construction programmes in Ghana, as can be seen in Table 1.

\subsection{Sampling Technique Adopted for the Study}

\subsubsection{Census Sampling}

This type of sampling technique was used to provide an opportunity for a level platform for all the professionals within the academic institutions selected for this research, who were only twenty-eight (28) respondents.

\subsubsection{Systematic Random Sampling}

Systematic sampling technique was adopted for the data collection from the industry by selecting the first 6th member of GIOC members on the list of the GIOC cooperate members and every 6 th on the list until the number of members was up to the required sample size needed for the study.

\subsection{Design of Questionnaire (Sequence \& Wording)}

The questions were designed such that, each was comparatively short, simple and easy for respondents to answer. They were structured to proceed in logical sequence moving in order of the study for easy understanding to respondents of the content and also to make it easy for research analysis. The shape of the questionnaire were designed such that respondents were asked to rank variables to determine the most imperatives variable of academia-industry collaborative research among twenty-nine (29) factors, each had a rank from 1 - 5 using the Likert scale. They were ranked 1 - 5 with Key: 1 = Disagree, 2 = strongly disagree, $3=$ Not sure, $4=$ Agree, 5 = strongly agree, as a means for brief direction for respondents to give their opinion by ticking one rank on each variable.

\subsection{Mode of Questionnaire Administration}

The administering of questionnaires was done by mail with follow-up telephone

Table 1. Population for academia-industry.

POPULATION

\section{ACADEMIA}

Department of Building Technology, KNUST-Kumasi, Ghana 15

A Faculty of Construction \& Wood Technology, UEW-Kumasi, Ghana 13

$\begin{array}{ll}\text { Sub-population (A) } & 28\end{array}$

\section{INDUSTRY}

B

$\begin{array}{ll}\text { Ghana Institute of Construction (GIOC) } & 710\end{array}$

$\begin{array}{ll}\text { Sub-population (B) } & 710\end{array}$

$\begin{array}{ll}\text { Total }(\mathrm{A}+\mathrm{B}) & 738\end{array}$

Researcher's survey (2016). 
calls to respondents who were distanced from the researcher as well as those who were too busy or it was difficult to get them face-to-face. The mailing enabled the researcher to cover a large number of its targets within the shortest period of time at a very low cost. A total of one-hundred and thirty (130) questionnaires were distributed to respondents; out of this one-hundred and two (102) questionnaires were sent to professionals in the industry and the remaining twenty-eight (28) questionnaires to the academician. Even though, one-hundred and sixteen (116) respondents were the target sample size set for this research, fourteen (14) extra was added to the respondents to run it up to 130 to make good for none return questionnaires, and also as a means of factor of safety to take care of the frustration and complexity in getting data from respondents based on previous similar studies.

\subsection{Data Collected}

A total of seventy-nine (79) retrieved questionnaire were answered by respondents out of the one-hundred and thirty (130), sixty-three (63) from the industry and sixteen (16) from the Academia. Though the target returns were to use the systematic approach to work with the first eighty-eight (88) respondents from the industry data and all of academia, the retrieved responses unfortunately was not up to 88. Therefore, all the sixty-three (63) questionnaires from the industry, plus the sixteen (16) from academia were used for the analysis of this research.

\section{Analysis and Discussion}

\subsection{Analysis of Data on Imperatives of Collaboration}

According to [27] and [28], a variable was deemed to be crucial or imperative for collaborative research if it scored a mean value of $\geq 2.5$ while variables with mean values $<2.5$ were deemed not crucial or trivial for collaborative research and therefore were automatically rejected. On the contrary, where two or more variables had the same mean; the one with the lowest Standard Deviation (SD) was considered to be the most crucial or the most imperative in ranking [27] and [28]. Table 2 is an illustration of the variables that were considered to be the imperatives of collaborative research. By observation, it can be clearly seen that all the variables had mean score values ranging from 3.0 and above, signifying all the 29 factors in Table 2 were the imperatives for academia and industry collaborative research in the construction industry in Ghana.

However, the result shows that the number one most imperative factor for collaborative research was for the purpose of solving socio-economic and development problem through collaborative research findings because this factor scored the highest mean value of 4.6456 than all the others, Environmental considerations, e.g., land degradation, air and water pollution, loss of habitats, was the second (2nd) most crucial imperative, also with a mean value of 4.2785, thirdly (3rd) was Intermittent collapse of buildings was the second most crucial 
Table 2. Imperatives of collaboration.

\begin{tabular}{|c|c|c|c|c|c|c|}
\hline \multicolumn{7}{|c|}{ Descriptive Statistics } \\
\hline & $\mathbf{N}$ & Min. & Max. & Mean & Std. Deviation & Rank \\
\hline $\begin{array}{l}\text { To solve socio-economic and development problem through collaborative } \\
\text { research findings }\end{array}$ & 79 & 3.00 & 5.00 & 4.6456 & 0.53200 & 1 st \\
\hline $\begin{array}{l}\text { Environmental considerations, e.g., land degradation, loss of habitats, air } \\
\text { and water pollution }\end{array}$ & 79 & 1.00 & 5.00 & 4.2785 & 1.01194 & 2nd \\
\hline Intermittent collapse of buildings & 79 & 1.00 & 5.00 & 4.2658 & 0.95688 & 3 rd \\
\hline $\begin{array}{l}\text { Support for the local industries to produce quality materials locally to feed } \\
\text { the construction industry }\end{array}$ & 79 & 1.00 & 5.00 & 4.2532 & 0.85438 & 4th \\
\hline Need for Training of professionals and artisans & 79 & 2.00 & 5.00 & 4.2278 & 0.76710 & 5 th \\
\hline Proper contract documentations $\&$ administration of projects & 79 & 2.00 & 5.00 & 4.2278 & 0.78364 & 6th \\
\hline Risk sharing, access to innovation and technology & 79 & 1.00 & 5.00 & 4.2025 & 1.01754 & 7th \\
\hline Complexity in construction of modern buildings designs & 79 & 2.00 & 5.00 & 4.1772 & 0.81271 & 8th \\
\hline For data and information sharing & 79 & 2.00 & 5.00 & 4.1646 & 0.79147 & 9th \\
\hline A shared vision ,common goal and priorities & 79 & 3.00 & 5.00 & 4.1266 & 0.80650 & 10th \\
\hline To break down barriers among institution and industry & 79 & 2.00 & 5.00 & 4.1139 & 0.73358 & 11th \\
\hline The motivation to boost productivity as well as increase economic growth & 79 & 1.00 & 5.00 & 4.0886 & 0.85019 & 12th \\
\hline Project planning \& site management & 79 & 1.00 & 5.00 & 4.0759 & 1.05942 & 13th \\
\hline Building trusting relationships among partners & 79 & 2.00 & 5.00 & 4.0759 & 0.79698 & 14th \\
\hline $\begin{array}{l}\text { Increase demands for customer information and satisfaction of } \\
\text { construction products }\end{array}$ & 79 & 2.00 & 5.00 & 4.0633 & 0.89646 & 15 th \\
\hline Response to market demand, resource efficiency and client requirements & 79 & 2.00 & 5.00 & 3.9747 & 0.78405 & 16th \\
\hline To set a definition of procedures for collaboration/work, clear & 79 & 2.00 & 5.00 & 3.8861 & 0.78426 & 17th \\
\hline To solve complexity of some research problems & 79 & 1.00 & 5.00 & 3.8608 & 1.04678 & 18th \\
\hline For commitment of adequate resources from partners & 79 & 1.00 & 5.00 & 3.7848 & 0.91527 & 19th \\
\hline To come out with a good form of communication procedures & 79 & 2.00 & 5.00 & 3.7342 & 0.84290 & 20th \\
\hline Publish a journal article, business issues and other expectations & 79 & 1.00 & 5.00 & 3.7089 & 1.07598 & 21 st \\
\hline Enhance the visibility and recognition of research partners & 79 & 1.00 & 5.00 & 3.6835 & 1.08065 & 22nd \\
\hline Massive continual increase in housing deficit & 79 & 1.00 & 5.00 & 3.6835 & 1.08065 & 23rd \\
\hline High cost of construction products & 79 & 1.00 & 5.00 & 3.6709 & 0.99642 & 24th \\
\hline Pressure exerted on institution/industries by their stakeholder groups & 79 & 1.00 & 5.00 & 3.5949 & 0.96767 & 25th \\
\hline High importation of construction materials & 79 & 1.00 & 5.00 & 3.4557 & 1.22785 & 26th \\
\hline $\begin{array}{l}\text { The desire to have dominion or power over other's resources such as } \\
\text { technology, raw materials, expertise etc. }\end{array}$ & 79 & 1.00 & 5.00 & 3.3038 & 1.10191 & 27th \\
\hline To be seen by others as legitimate & 79 & 1.00 & 5.00 & 3.3038 & 1.14751 & 28th \\
\hline $\begin{array}{l}\text { To enable partners get the opportunity to use expensive equipment they } \\
\text { cannot afford or get }\end{array}$ & 79 & 1.00 & 5.00 & 3.0380 & 1.17061 & 29th \\
\hline
\end{tabular}

Researcher's survey (2016). 
imperative, also with a mean value of 4.2658 , fourth (4th) most imperative was support for the local industries to produce quality materials locally to feed the construction industry with mean value of 4.2532 .

Need for Training of professionals and artisans with SD of 0.76710 was the next highest as the 5th, followed by Proper contract documentations \& administration of projects with SD 0.78364 as 6 th. Even though the 5th and 6th both had the same mean score of 4.2278 , yet still the most considering imperative factor was established using their different standard deviation as stated earlier, where two or more variables have the same mean the SD can be used to give a clear distinction by their variation or divergence of respondents opinion on a factor. The smaller the SD, the higher the consistency of the variable since there is little in disagreement of opinion. While higher SD implies large divergence or inconsistency in opinions, therefore, the result may be unreliable because of the large variations in opinions making it weak.

The last column on Table 2 highlights the most crucial imperative factors, by ranking all the variables in descending order from the most crucial to the least imperative variables for collaborative research using their mean and standard deviation values. Thus, as follows, Risk sharing, access to innovation and technology (7th with mean 4.2025), Complexity in modern designs construction (8th, mean 4.1772), Again, for data and information (9th, mean 4.1646, SD 0.79147), and a shared vision, common goal and priorities (10th, mean 4.1646, SD 0.80650). It should be noted that the 9th and 10th variables had the same mean value; therefore, the SD was used to make a distinction among them, also, to break down barriers among institutions and the industry (11th, mean 4.1139). This continues respectively as can be seen easily in descending order on the ranking column of the table explicitly presented from 1st to 29th on all the factors. To enable partners get the opportunity to use expensive equipment that is not under their control had the least mean of 3.0380, explaining why is 29th on the ranking.

\subsection{Discussion on Analysis on the Imperatives of Collaboration}

Studies conducted by [17] [19] [29], and affirmed collaborative research as a necessary tool to overcome some degree of risk, accountability as well as the complexity of some research problems, through sharing or spreading among partners to merge their expertise and resources to assure that research findings solve socio-economic and development problems and making it easier than an individual establishment or administration can deal with [30] [31] and [32] were of the same view that, the imperatives of collaborative research include; inappropriate contract conditions, incomplete contract documents, materials control on the site, lack of skilled labour, project planning and site management, technical know-how, environmental considerations, excessive resource consumption, land degradation, loss of habitats, air and water pollution, and high energy usage. Although, [6] and [7] study identified one of the key benefits to academia-industry 
to be enabling academia to get opportunity to use expensive equipment of the industry they cannot afford or get, the result from the study gives a contrary view to this point. This is shown clearly on Table 2 with enabling partners (academia) to get opportunity to use expensive equipments they cannot afford or get, considered to be the least imperative to academia-industry collaborative research in the Ghanaian construction industry ranked 29th with the least mean value of 3.038. [3] opined, the intermittent collapse of buildings in the two major capital cities in Ghana, the high cost of building materials, inadequate support for the local industries to produce quality materials locally to feed the construction industry, also the problems and inefficiencies in the construction industry in the country. These inefficiencies and many other imperatives call for immediate attention and redress, partly through the initiative of academia and industry collaborative research, and networking with the government and all industry stakeholders to salvage the situation. In a similar study, numerous researchers such as [10] [19] [26] [33] revealed that a common goal, shared vision, benefit to partners, equal powers to function, to achieve a "win-win" agenda and so on, there would be the need for all the various partners in a collaborative research agenda to align their individual resources towards a common aim that serve the interest of all partners.

\section{Conclusions/Recommendations}

The main objective of this research was to establish the most imperatives factors for academia-industry collaborative research in the Ghanaian construction industry. The study revealed that the most imperatives for academia-industry collaborative research in the construction industry is to solve socio-economic and development problem through collaborative research findings, environmental considerations for instance; land degradation, loss of habitats, air and water pollution, and intermittent collapse of buildings were discovered to be the major imperatives scholars and industry players that should make concrete effort to come out with finding relevant to support the local industries to produce quality materials locally to feed the construction industry among others.

The researchers recommend that academia and industry should start collaboration in applied research areas that address immediate needs in the Ghanaian construction industry such as, how to reduce the housing deficit in Ghana, as well as how to come out with alternative local or indigenous material to compete with foreign materials to serve the construction needs of Ghana.

Furthermore, future research should be directed towards findings to come out with high quality building constructions at low cost, how to set best construction practices, and ways to produce energy efficiency buildings among others.

\section{Conflicts of Interest}

The authors declare no conflicts of interest regarding the publication of this paper. 


\section{References}

[1] National Council of University Research Administrators and the Industrial Research Institute (2006) Guiding Principles for University-Industry Endeavors. Report of a Joint Project April, 2006.

[2] Lee, Y.S. (2000) The Sustainability of University-Industry Research Collaboration: An Empirical Assessment. The Journal of Technology Transfer, 25, 111-133. https://doi.org/10.1023/A:1007895322042

[3] Bediako, M. (2015) Teach Project Management. https://www.ghanaweb.com

[4] Yeung, N.S.Y. and Chan, A.P.C. (2002) Collaborative Research Better Value for Construction. Project Management Impresario of the Construction Industry Symposium, Kowloon, Hong Kong, 22-23 March 2002, 34-41. http://www.bre.polyu.edu.hk/rccree/events/pm_symposium/NicloasYeung.pdf

[5] Narin, F., Stevens, K. and Whitlow, E.S. (1991) Scientific Co-Operation in Europe and the Citation of Multi-Nationally Authored Papers. Scientometrics, 21, 313-324. https://doi.org/10.1007/BF02093973

[6] Meadows, A.J. and O’Connor, J.G. (1971) Bibliographic Statistics as a Guide to Growth Points in Science. Science Studies, 1, 95-99. https://doi.org/10.1177/030631277100100107

[7] Schubert, T. and Sooryamoorthy, R. (2010) Can the Centre-Periphery Model Explain Patterns of International Scientific Collaboration among Threshold and Industrialised Countries? The Case of South Africa and Germany. Scientometrics, 83, 45. https://doi.org/10.1007/s11192-009-0074-2

[8] Beaver, D. and Rosen, R. (1978) Studies in Scientific Collaboration: Part I-Professional Origins of Scientific Co-Authorship. Scientometrics, 1, 65-84. https://doi.org/10.1007/BF02016840

[9] Anastassios Pouris, Y.-S.H. (2013) Research Emphasis and Collaboration in Africa. Scientometrics, 98, 2169-2184. https://doi.org/10.1007/s11192-013-1156-8

[10] Shelbourn, M, Bouchlaghem, N.M., Anumba, C. and Carrillo, P. (2012) Planning and Implementation of Effective Collaboration in Construction Projects. Construction Innovation, 7, 357-377. https://doi.org/10.1108/14714170710780101

[11] Anand, B. and Khanna, T. (2000) Do Firms Learn to Create Value? The Case of Alliances. Strategic Management Journal, 21, 295-315. https://doi.org/10.1002/(SICI)1097-0266(200003)21:3<295::AID-SMJ91>3.0.CO;2$\underline{\mathrm{O}}$

[12] Hoffmann, W.H. and Schaper-Rinkel, W. (2001) Acquire or Ally a Strategic Framework for Deciding between Acquisition and Collaboration. Management International Review, 41, 131-59.

[13] Das, T.K. and Teng, B.S. (1998) Between Trust and Control: Developing Confidence in Partner Cooperation in Alliances. Academy of Management Review, 23, 491-512. https://doi.org/10.5465/amr.1998.926623

[14] Belderbos, R. Carree, M. and Lokshin, B. (2004) Cooperative R\&D and Firm Performance. Research Policy, 33, 1477-1492. https://doi.org/10.1016/j.respol.2004.07.003

[15] Alvarez, R. (2001) 'It Was a Great System' Face Work and Discursive Construction of Technology during Information Systems Development. Information Technology \& People, 14, 385-405. https://doi.org/10.1108/EUM0000000006518

[16] Vakola, M. and Wilson, I.E. (2002) The Challenge of Virtual Organisation: Critical Success Factors in Dealing with Constant Change. Team Performance Management: 
An International Journal, 10, 112-120.

[17] CDD-Ghana (2005) The Challenges of Collaborative Policy Research/Research Ethics. The Ghana Centre for Democratic Development CDD at the Research and Advocacy Organizations Convention Friday 13 May 2005.

[18] Fiedler, T. and Deegen, C. (2007) Motivations for Environmental Collaboration within the Building and Construction Industry. Managerial Auditing Journal, 22, 410-441. https://doi.org/10.1108/02686900710741946

[19] Oliver, C. (1990) Determinants of Interorganizational Relationships: Integration and Future Directions. Academy of Management Review, 15, 241-265. https://doi.org/10.5465/amr.1990.4308156

[20] Levine, S. and White, P. (1961) Exchange as a Conceptual Framework for the Study of Interorganizational Relationships. Holt, Rinehart \& Winston, New York, 29-47. https://doi.org/10.2307/2390622

[21] Cockburn, I. and Henderson, R. (1998) Absorptive Capacity, Coauthoring Behavior, and the Organization of Research in Drug Discovery. Journal of Industrial Economics, 46, 157-182. https://doi.org/10.1111/1467-6451.00067

[22] Zucker, L., Darby, M.R. and Armstrong, J.S. (2002) Commercializing Knowledge: University Science, Knowledge Capture, and Firm Performance in Biotechnology. Management Science, 48, 138-153. https://doi.org/10.1287/mnsc.48.1.138.14274

[23] Banal-estañol, A., Macho-stadler, I. and Pérez-castrillo, D. (2013) Research Output from University-Industry Collaborative Projects. Economic Development Quarterly, 27, 71-81. https://doi.org/10.1177/0891242412472535

[24] Amabile, T.M., Patterson, C., Mueller, J., Wojcik, T., Odomirok, P.W., Marsh, M., and Kramer, S.J. (2001) Academic-Practitioner Collaboration in Management Research: A Case of Cross-Profession Collaboration. The Academy of Management Journal, 44, 418-431.

[25] Barnes, T., Pashby, I. and Gibbons, A. (2002) Effective University-Industry Interaction: A Multi-Case Evaluation of Collaborative R\&D Projects. European Management Journal, 1, 272-285. https://doi.org/10.1016/S0263-2373(02)00044-0

[26] Katz, J.S. and Martin, B.R. (1997) What Is Research Collaboration? Research Policy, 26, 1-18. https://doi.org/10.1016/S0048-7333(96)00917-1

[27] Field, A.P. (2005) Is the Meta-Analysis of Correlation Coefficients Accurate When Population Effect Sizes Vary? Psychological Methods, 10, 444-467. https://doi.org/10.1037/1082-989X.10.4.444

[28] Adinyira, E., Fugar, F.D. and Osei, A. (2011) Underlying Factors for Construction Research Collaboration in Ghana. Proceeding 6th Built Environment Conference, Vol. 6, August 2011, 385-399.

[29] Smith, D. and Katz, J.S. (2000) Collaborative Approaches to Research. A Joint Project with the Higher Education Policy Unit (HEPU), University of Leeds and the Science Policy Research Unit (SPRU), University of Sussex, Falmer.

[30] Lamudi (2014) Challenges Facing Real Estate Development in Ghana. http://lamudi.com.gh/journal/9-challenges-facing-real-estate-development-ghana

[31] Laryea, S.A. (2010) Challenges and Opportunities Facing Contractors in Ghana. West Africa Built Environment Research Conference, Accra, 27-28 July 2010, 215-226.

[32] Ofori, G. (2012) Developing the Construction Industry in Ghana: The Case for a Central Agency.

http://www.ghanatrade.gov.gh/./Developing\%20the\%20Construction\%20Industry 
[33] Golicic, S.L., Foggin, J.H. and Mentzer, J.T. (2003) Relationship Magnitude and Its Role in Inter-Organizational Relationship Structure. Journal of Business Logistics, 24, 57-75. https://doi.org/10.1002/j.2158-1592.2003.tb00032.x 